\title{
Mecanicismo y teleología: resonancias de la concepción aristotélica de lo viviente en la fenomenología de M. Merleau-Ponty
}

FERNANDO LIBONATI

Universidad de Buenos Aires

\begin{abstract}
Resumen: Se plantea una aproximación conceptual entre la caracterización de lo viviente en Aristóteles y Merleau-Ponty. Partiendo del concepto de necesidad hipotética, se sostiene la compatibilidad de causas materiales y finales en el corpus aristotélico, relacionando los tratados biológicos con De Anima y Metafísica. Siguiendo a Allan Gotthelf (1987), se afirma la irreductibilidad de los procesos orgánicos. Posteriormente se presenta la noción merleau-pontyana de forma y su análisis de la teleología. Se destaca la reivindicación de lo viviente en la fenomenología merleau-pontyana, en tanto prioriza las funciones sobre los elementos componentes, y explicita las deficiencias y ambigüedades explicativas de las teorías dualistas o reduccionistas clásicas. Finalmente, se concluye que Merleau-Ponty reconoce a lo viviente las mismas características distintivas que Aristóteles.
\end{abstract}


Palabras clave: necesidad hipotética; alma; función; patología; reflejo.

\title{
Mechanism and Teleology: Echoes of the Aristotelian Conception of the Living in M. Merleau-Ponty's Phenomenology
}

\begin{abstract}
It is posed a conceptual convergence between the conception of the living in Aristotle and Merleau-Ponty. Based on the concept of hypothetical necessity, it is claimed the compatibility of material and final causes in the Aristotelian corpus, by linking the biological treatises with De Anima and Metaphysics. Following Allan Gotthelf (1987), it is stated the irreducibility of organic processes. Subsequently it is presented the merleau-pontyan notion of form and his analysis of teleology. It is emphasized the vindication of the living in Merleau-Ponty's phenomenology, inasmuch as it prioritizes functions over component elements and exhibits the deficiencies and ambiguities of dualistic and reductionist classical theories. Finally, it is concluded that Merleau-Ponty recognizes to the living the same hallmarks as Aristotle.
\end{abstract}

Key-words: hypothetical necessity; soul; function; pathology; reflex.

\section{Introducción}

— $\mathrm{n}$ los estudios dedicados a la relación entre Aristóteles y Merdencias, principalmente con respecto al rol de la percepción en los procesos cognitivos (Pagni 2012; Honorato 2018). En lo tocante al carácter impersonal de la percepción, así como a la interdependencia entre sentido y sintiente, se han puntualizado asimismo similitudes y diferencias (Stevens 2002). Finalmente, se han destacado algunas tensiones relativas a su concepción de la naturaleza (Fóti 1999). En la mayoría de los estudios mencionados, las obras que se toman como representantes del corpus aristotélico son principalmente Acerca del Alma y Metafísica. La investigación del presente trabajo puede pensarse como continuidad y complemento de los escritos referidos, en tanto se propone profundizar sobre el vínculo entre las mencionadas obras aristotélicas y sus tratados biológicos como Partes de los Animales y Reproducción de los Animales, a fin de explicitar la ontología de lo viviente desarrollada y elucidar posibles parentescos conceptuales con la caracterización de lo viviente en la 
fenomenología merleau-pontyana, atendiendo específicamente a la relación entre explicaciones mecánicas y teleológicas.

\section{La reivindicación aristotélica de lo orgánico frente al atomismo y al platonismo}

\subsection{Necesidad material, teleología y necesidad hipotética: una definición general de lo viviente}

A juzgar por la cantidad de trabajos dedicados al asunto, uno de Alos fenómenos que despertó mayor interés en Aristóteles fue la diversidad, complejidad y regularidad de los seres vivos. Sus órganos y miembros presentaban una adecuación a sus necesidades o beneficios demasiado eficiente, sofisticada y frecuente como para aceptar que su explicación pudiera reducirse a una asociación azarosa de los mismos elementos que conformaban los cuerpos inanimados, o bien a las reacciones que necesariamente suceden en virtud de la interacción de sus cualidades (en adelante nos referiremos a este último proceso como "necesidad material"). Absorber los nutrientes (y eventualmente transmitirlos a las crías), conservar determinada temperatura, contar con capacidades perceptivas y motrices que permitan refugiarse, migrar, reproducirse o conseguir alimento, entre otras, son funciones cuya generación y mantenimiento no parecía resultar de la mera necesidad material sin hacer referencia a algún propósito o finalidad. Así, Aristóteles se distinguía de Demócrito y Empédocles, quienes no contemplaban la causa final en sus explicaciones sobre el origen y desarrollo de los procesos orgánicos. ${ }^{1}$ Mas al filósofo tampoco le satisfizo la idea de hipostasiar una inteligencia trascendente que, a la manera de un artesano, hubiera creado a los seres vivos de acuerdo con un plan representado previamente. De manera que su posición también se distanciaba de la idea platónica del demiurgo (Platón Timeo, 72e-92c). ${ }^{2}$

Frente a tales posturas, Aristóteles plantea la idea de una teleología inmanente, a fin de explicar la existencia y desarrollo de los órganos y sus funciones por referencia a un orden que no puede reducirse a las propiedades de sus elementos componentes, pero que tampoco es una instancia

\footnotetext{
${ }^{1}$ Para Empédocles, véase DK 31 B 57, 60, 61; para Demócrito, véase DK 67 A 14, 68 A 1, 37, 39, 49, 57, 64.

${ }^{2}$ Véase también Pagni 2012: 55, 79-80.
} 
trascendente, sino que radica en los vivientes mismos. Desde luego, el desafio de justificar semejante postura exigió una observación variada, minuciosa y sistemática de los seres vivos, así como la elaboración de un marco teórico adecuado para expresar las relaciones entre biología y metafísica que su proyecto implicaba.

De acuerdo con la revisión presentada en Metafísica A 3, 983 b5 ss., la idea de una causa final constituye una innovación de la filosofía aristotélica respecto de sus predecesores. Pues estos reconocieron únicamente la causa material como principio, atendiendo a que su entidad permanece a pesar de la generación, descomposición o cambios accidentales. Así, alguno de los cuatro elementos, una combinación de ellos, o todos, bastaban para dar cuenta de la naturaleza. No obstante, estos primeros filósofos advirtieron inmediatamente que los elementos mismos no podían ser causas de los cambios de los que se admitía eran el soporte, o de su belleza o bondad. Entonces debieron ocuparse de investigar sus principios de movimiento, entre los cuales algunos postularon un único principio, como el amor, y otros, un par de contrarios como la amistad y el odio, para dar cuenta del orden y el bien, y el desorden y el mal, respectivamente. En este punto consideramos importante destacar el reconocimiento que Aristóteles concede a Anaxágoras por haber sostenido que "al igual que en los animales, hay también en la Naturaleza un entendimiento, causa de la belleza y del orden universal" (Met A 3, 984b15-17). Si bien le objeta no haber hecho un uso racional de dicha causa, consideramos que el reconocimiento puede interpretarse como un antecedente de su idea de teleología inmanente.

Con la filosofia de Platón, el principio de la naturaleza y de sus cambios deja de ser la materia, pues se asume en un continuo devenir que impide teorizar acerca de ella. Siguiendo el método socrático de definición en cuestiones éticas, Platón sostuvo que la esencia o definición de las cosas radica en las Formas, pertenecientes al ámbito inteligible, de las cuales participa la multiplicidad de entes del ámbito sensible.

Si bien esta postura tiene el mérito de reconocer que la causa de la existencia y movimiento de la naturaleza no puede reducirse a la materia, Aristóteles le critica "haber dejado de lado la investigación acerca de qué pueda ser la participación o imitación de las Formas” (Met A 6, 987b13-14), y mantener su investigación en el nivel de los conceptos (Met A 6, 987b30).

Esta breve presentación de la revisión crítica de sus predecesores contribuye a delimitar y aclarar tanto el proyecto de investigación aristotélico como su concepción de lo viviente. En efecto, encontramos que el filósofo rechaza tres posiciones: i) que la forma actual de los seres vivos sea producto de una asociación azarosa (Empédocles); ii) que la existencia y desarrollo de los procesos orgánicos pueda reducirse a la necesidad material (Demócrito); 
iii) que la existencia y desarrollo de los procesos orgánicos sea producto de un agente externo a la naturaleza (Platón).

Examinemos a continuación cómo resuelve Aristóteles la propuesta de articular la idea de una causa final con aquella, en apariencia incompatible, de que los procesos naturales ocurren por necesidad, exclusivamente a causa de las propiedades de los elementos.

En las Partes de los Animales, el filósofo sostiene que, entre las causas del principio del movimiento en el devenir natural, la que indica el para qué (causa final), tiene prioridad sobre la que indica el a partir de qué (causa eficiente) (PA I 2, 639b10-20), e inmediatamente introduce una distinción fundamental para la interpretación que intentamos defender:

Por otra parte, el principio de necesidad no afecta por igual a todos los hechos de la naturaleza, aunque casi todo el mundo trata de conducir a él sus explicaciones, sin distinguir en cuántos sentidos se dice "lo necesario". Por un lado, la necesidad absoluta solo existe para los seres eternos, mientras la necesidad condicional se da tanto en todos los seres sujetos al devenir natural, como en los productos técnicos. (PA I 2, 639b21-25).

Por un lado, entonces, existe una necesidad absoluta que rige exclusivamente a los seres eternos, pero, por otro, existe también una necesidad condicional que rige a los seres sujetos a devenir natural. Ahora bien, se ha dicho que en el devenir natural tiene prioridad la causa final. Por lo tanto, resta explicar en qué consiste la necesidad condicional y cuál es su relación con la causa final. Al respecto, en Física II 9 se aclara la articulación entre ambas.

Nada podría ser hecho sin cosas que tengan la naturaleza necesaria para ello, pero no es hecho por causa de ellas (excepto como su materia), sino para algo. Por ejemplo: ¿por qué una sierra está hecha así? Con vistas a esto y para esto. Pero aquello para lo cual se ha hecho no se puede cumplir si no está hecha de hierro. Es pues necesario que sea de hierro, si ha de ser una sierra y cumplir su función. Luego lo necesario es necesario condicionalmente, pero no como fin; porque la necesidad está en la materia, mientras que el fin está en la definición. (Fis. II 9, 200a7-15. Las cursivas son nuestras).

En el pasaje citado se aclara explícitamente que si bien las propiedades de determinada/s materia/s resultan condición necesaria para la existencia y función que ha de cumplir cierto objeto o cuerpo, de ningún modo estas pueden considerarse condición suficiente de su formación, puesto que el fin para el que se realiza -que es justamente lo que exige la concurrencia de ciertos elementos y no otros- no es una propiedad de la materia misma. En 
otras palabras, así como en la sierra la función de cortar no es producto del hierro en tanto materia, en los órganos, sus funciones no son producto de sus elementos componentes. En este sentido se comprende que Aristóteles presentara la idea de causa final como una innovación frente a sus predecesores, justamente por demostrar que no puede reducirse a ninguno de los tipos de causas preexistentes.

La aplicación de esta tesis (i.e. la prioridad de la causa final) al campo de la biología estructura el método de investigación del tratado sobre las partes de los animales. En su descripción, el filósofo se refiere nuevamente a la noción de necesidad hipotética citada, presente también en Metafísica 1015a20:

Por ello precisamente hay que decir que dado que esta es la esencia del hombre, por eso tiene estas partes, pues no es posible que exista sin ellas (...). Puesto que es tal, es necesario que su proceso de formación suceda así y de tal forma. Por eso una parte se forma primero, luego otra. Y de la misma manera igual para todos los organismos naturales. (PA I 3, 640a33-b4). ${ }^{3}$

La esencia o definición de cada ser vivo consiste en la posesión de determinados órganos o miembros que permitan el cumplimiento de sus funciones, las cuales solo pueden realizarse gracias a las propiedades de ciertas materias (necesidad material). Sin embargo, esto no implica que la esencia o función sea un producto de la necesidad material. Por el contrario, un ser vivo no es tal porque existan las partes que lo componen, sino que dichas partes existen y adquieren cierta configuración si ha de generarse un ser de tal tipo. En términos aristotélicos, esta relación expresa la prioridad ontológica, lógica y epistemológica de la causa final en la existencia y desarrollo de los procesos orgánicos, sobre la que el filósofo insiste en reiteradas ocasiones contra Demócrito y Empédocles. ${ }^{4} Y$ puesto que la forma y función de cada órgano, y del conjunto, viene dada por el alma, es que concierne al naturalista "hablar sobre el alma y conocerla" (PA I 4, 641a21-22), a los efectos de poder estudiar "los accidentes de acuerdo con su propia esencia" (PA I 4, 641a24-25). En este sentido cabe interpretar que la inclusión del estudio del alma dentro de la fisica indica que el conocimiento de esta última estaría incompleto sin un conocimiento de la primera.

Por lo visto, el concepto de necesidad hipotética permite articular la prioridad de la causa final con la necesidad material. Pues si bien remite

\footnotetext{
${ }^{3}$ Véase también $P A$ I 6, 642a1-15.

${ }^{4} P A$ I 3, 640a20-25, 640b5-641a15; RA V 2, 778b1-10, V 24, 789b1-20.
} 
inevitablemente al alma o esencia en tanto aquello que prescribe la función o definición de un ser vivo, indica asimismo que esta puede realizarse únicamente gracias a las propiedades de determinadas materias (necesidad material). De esta manera, la explicación basada en necesidad material no queda excluida de los fenómenos naturales, ni tampoco reducida a la teleología, sino más bien subordinada a esta en ciertos casos. Al respecto, adherimos a la postura de Cooper (1987: 264) y Boylan (1981). En suma, en palabras del propio Aristóteles, el objeto de las investigaciones biológicas es mostrar que la génesis depende y se desarrolla en virtud de la existencia, y no, a la inversa, que la existencia depende de la génesis, como se deduce de las posiciones materialistas que no contemplaron la causa final. ${ }^{6}$

No obstante, a pesar de las críticas a sus predecesores, el filósofo justifica en cierto modo sus posiciones, puesto que "no les era posible conocer la esencia, ni definir la sustancia" (PA I 7, 642a25-26). Ahora bien, aunque el marco teórico desarrollado brinda argumentos coherentes y convincentes, el mismo debe complementarse con el aporte de evidencia empírica. En otras palabras, Aristóteles se propone explicitar cómo esa esencia o definición que establece el fin al que se subordinan las necesidades materiales efectivamente opera en la naturaleza a efectos de generar seres de determinado tipo. Tal fundamentación es el objeto de Reproducción de los Animales y de parte de Acerca del Alma.

\subsection{El papel del alma en la reproducción de los animales}

Dara abordar el problema planteado al final del apartado anterior, asumimos con Gotthelf (1987) que la cuestión del significado de la teleología debe analizarse formulando la posibilidad del reduccionismo.

\footnotetext{
${ }^{5}$ Balme (1939) ofrece buenos argumentos en contra de esta interpretación. Consideramos de particular interés los siguientes: i) la idea de un orden mecánico (sin acción de causas finales) es inconcebible en el pensamiento aristotélico, por lo que la necesidad material no podría ser complementaria sino solo excluyente respecto de la teleología (p. 135-7); ii) la distinción entre los procesos que obedecen a causas materiales/eficientes y los que obedecen a causas formales/finales carece de legitimidad, además de presentar una gran dificultad (p. 133); iii) la compatibilidad de necesidad material y teleología implica la existencia de dos tipos o niveles de leyes que en ciertos fenómenos se excluyen mutuamente, como en el caso de las monstruosidades ( $R A$ IV 17, 770b10-20), lo cual hace equívoco al concepto de physis (p. 132-3); finalmente, iv) la cuestión del azar, que resulta problemática tanto para la interpretación de Balme como para la nuestra.

${ }^{6}$ Véase nota 4.
} 
En palabras del autor, debemos preguntarnos:

¿Es el desarrollo de un organismo viviente el resultado de una suma de actualizaciones de potencias de elementos, o es principalmente la actualización de una potencia para un organismo de determinada forma, una potencia cuya actualización incluye la actualización de potencias de elementos, pero no es reductible a ellas? (Gotthelf 1987: 212).

A continuación presentamos brevemente el proceso de concepción y desarrollo del embrión en Reproducción de los Animales, a fin de explicitar la imposibilidad de explicarlo en términos de necesidad material, dada la centralidad que Aristóteles atribuye al alma como elemento finalista.

La teoría aristotélica de la reproducción se construye como respuesta a los defensores de la pangénesis y la preformación. Los primeros sostenían que el esperma proviene de todas las partes del cuerpo por igual; los segundos afirmaban que el macho y la hembra poseen cada uno, en acto, una mitad de las partes de su descendiente ( $R A$ I 20, 721b5-35; I 22, 722b1-724a15). La refutación y superación de dichas posturas se sigue del desarrollo de la reproducción propuesto por Aristóteles.

El esperma es un residuo del alimento en su fase final de asimilación y cocción, esto es, una vez convertido en sangre ( $R A$ I 27, 726b1-20). En el macho, cuya temperatura es superior a la hembra, una parte de la sangre es sometida a un proceso ulterior de cocción, que la convierte finalmente en esperma. La sangre es lo que se distribuye por el cuerpo formando sus partes, de manera que posee cada una de ellas en potencia. El esperma, en tanto residuo de la sangre, posee sus mismas potencias (i.e. cada parte del cuerpo). De esta manera se explica que la cría generada por ese esperma sea semejante a su progenitor, sin recurrir a la formación de esperma en cada parte del cuerpo, ni a la preexistencia en acto de las partes en cada uno de los progenitores. Sin embargo, a pesar de esta aclaración sobre la naturaleza del esperma, la generación aún podría explicarse en términos de necesidad material, prescindiendo de la causa final. Es en el libro II de Reproducción de los Animales donde se explicita el papel del alma como elemento finalista.

Luego de afirmar que la finalidad de la reproducción es la participación del individuo, en tanto miembro de una especie, en la eternidad ( $R A$ II 1,731b25-732a10), ${ }^{7}$ Aristóteles indaga el proceso de desarrollo del embrión.

\footnotetext{
${ }^{7}$ Véase también De an. II 4, 415a25-415b1.
} 
$\mathrm{Al}$ respecto, sostiene que el esperma actúa sobre el residuo menstrual que aporta la hembra, el cual es identificado con la materia. Ahora bien, el factor que actúa sobre el residuo no es ninguna propiedad de la materia del esperma, presente actualmente en el mismo, ${ }^{8}$ pues esta se evapora por ser de naturaleza húmeda y acuosa, quedando solo su aire caliente innato (pneûma), donde radica su fecundidad ( $R A$ II 9, 736b30-737a15). En este punto es oportuno destacar una distinción que apoya nuestra interpretación de la irreductibilidad del elemento finalista: el calor del pneûma es de distinta especie que el producido por el fuego, incapaz de generar seres vivos $(R A$ II 9,736b30-737a15). Habiendo descartado la causa material y la presencia en acto, es preciso que sea una potencia la que actúe en primer término sobre el residuo. Esta potencia que radica en el esperma es su alma $(R A$ II 9, 736b5-15, 737a15-20), y es actualizada por un movimiento en acto transmitido al esperma por su generador. Como resultado, se inicia un movimiento ulterior en el esperma, que finalmente actualiza las potencias del residuo de la hembra ( $R A$ II 10,737a20-25), dando comienzo a la formación de las partes.

Puesto que la formación descripta resulta de la actualización del alma en potencia en el esperma, el desarrollo de los órganos se produce conforme a la prioridad de las capacidades o funciones que constituyen la esencia del ser en cuestión. Considerando que la función principal y más básica es la nutritiva, lo primero en formarse es el órgano que posibilita su cumplimiento, es decir, el corazón (o su análogo en otros animales). Aristóteles parece confirmar esta organización finalista en el proceso al sostener que "de alguna manera es el movimiento que está dentro de él [del esperma], igual que el proceso de construcción con respecto a la casa" ( $R A$ II 6, 734b16-17). ${ }^{9} \mathrm{El}$ siguiente pasaje de Reproducción de los animales explicita esta relación:

Pues no hay cara ni carne sin alma (...) y de la misma forma que no afirmaríamos de un hacha ni de otro instrumento que los ha hecho solo el fuego así tampoco lo diríamos de un pie o de una mano.Y del mismo modo, tampoco de la carne:

\footnotetext{
8 "Está claro, entonces, que hay algo que actúa, pero no una cosa determinada ni presente en el semen como algo acabado desde el principio" ( $R A$ II 6, 734b17-19).

${ }^{9}$ Se podría objetar a esta interpretación que, en tanto es un movimiento lo que actualiza las potencias del residuo, bastaría identificarlo con la causa eficiente, sin necesidad de recurrir a un componente finalista. En contra de esta posición, seguimos a Gotthelf (1987: 227 n.52, 232 ss.): la potencia (o su portador) podría identificarse con la causa eficiente -no sin cierta dificultad, pues la causa eficiente no podría dar cuenta de la organización con que se desarrolla el proceso-, pero esta identificación no es válida para aquello de lo que la potencia es potencia.
} 
pues también esta tiene su función. En efecto, dureza, blandura, resistencia, fragilidad y todas las demás cualidades de este tipo que poseen las partes animadas, el calor y el frío las producirían; pero ellos no serían la causa de la definición en virtud de la cual una parte es ya carne y otra hueso, sino que esto lo produciría el movimiento procedente del generador, que es en acto lo que en potencia es aquello de donde se forma el nuevo ser. ( $R A$ II 7,734b24-36. Las cursivas son nuestras).

Retomando la pregunta inicial de esta sección, podemos concluir que el orden que la actualización de la potencia del esperma impone al desarrollo no puede reducirse a la actualización de sus elementos componentes. ${ }^{10}$ En este punto coincidimos con Gotthelf:

Si esto es así, entonces la "potencia" que se manifiesta en el movimiento del semen también debe ser identificada por referencia a la forma que está siendo transmitida: es, fundamentalmente, una potencia para una forma, una potencia distinta de y no reductible a ninguna suma de potencias cualitativas y motoras (Gotthelf 1987: 217).

A fin de destacar el abordaje interdisciplinario que implica la concepción aristotélica de lo viviente, a continuación analizaremos algunos pasajes de Acerca del Alma que pueden interpretarse en apoyo de la irreductibilidad de la causa final.

En primer lugar, en consonancia con las críticas al materialismo, la definición de alma ofrecida en el libro II (1, 412a20-30), implica que esta no puede identificarse con la materia, pues se trata de una actualidad, mientras que la materia es una potencia; asimismo, el alma está entre las cosas que se dicen de un sustrato, mientras que la materia es dicho sustrato. Si el alma se identificara con la materia, todo cuerpo natural sería animado.

Por otra parte, con respecto a la relación entre necesidad material y finalidad, en el tratamiento del alma se reitera el postulado de que ciertas funciones esenciales, por definición, requieren determinadas materias u órganos para realizarse, pero no por eso se reducen a ellos:

\footnotetext{
${ }^{10}$ Podría objetarse a nuestra interpretación que el residuo de la hembra contiene todas las partes del organismo en potencia. Sin embargo, creemos que esto no habilita a sostener una posición reduccionista por dos razones. La primera es que las potencias del residuo necesitan el movimiento proveniente del alma en el esperma para actualizarse, lo cual no es un elemento. La segunda es que aunque las partes están contenidas, no lo está el orden en que deben desarrollarse para adecuarse a la esencia del ser en cuestión. Véase nota 9.
} 
$\mathrm{Y}$ es que la Naturaleza se sirve del aire inspirado para una doble actividad (...) no solo con vistas a regular la temperatura interior como algo necesario (...) sino también con vistas a la voz, de manera que se añada una perfección al que la posee (...) La voz es el golpe del aire inspirado, por la acción del alma residente en estas partes del cuerpo, contra lo que se denomina tráquea. Y, como ya dijimos, no todo sonido de un animal es voz (...) sino que ha de ser necesariamente un ser animado el que produzca el golpe sonoro y este ha de estar asociado a alguna representación (...) Por lo demás, la voz se emite al hacer que golpee contra la tráquea el aire contenido en ella sirviéndose al efecto del inspirado. (De an. II 8, 420b16-421a1, Aristóteles 1978). ${ }^{11}$

En este caso, la tráquea es condición necesaria para que haya voz, pues esta resulta del golpe del aire inspirado contra aquella. Pero la tráquea no puede considerarse condición suficiente, ya que no toda vez que el aire inspirado la golpea se produce voz, sino solo cuando este posee determinados movimientos que el alma le imprime a fin de expresar una representación a la que se asocia. Así, el componente finalista de la voz, i.e., el bienestar o perfección, solo se explica recurriendo al alma.

Por último, un pasaje que establece explícitamente la irreductibilidad de los procesos orgánicos a la necesidad material, y que complementa la distinción entre el pneûma y el calor del fuego postulada en Reproducción de los Animales (II 9, 736b30-737a15), es el siguiente:

Pero algunos creen que la naturaleza del fuego es causa en sentido estricto de la alimentación y del crecimiento (...) Sin embargo, [el fuego] es, en cierto modo, concausa, no causa en sentido estricto, sino que, más bien [es causa en sentido estricto] el alma. Pues el crecimiento del fuego va al infinito, hasta que haya [algo] combustible, en tanto que de todas las cosas que se constituyen por naturaleza hay un límite, es decir, una proporción, tanto de su magnitud como de su crecimiento. Estas características son propias del alma, no del fuego, de la forma más que de la materia. (De an. II 4, 416a9-18, Aristóteles 2010. Las cursivas son nuestras).

Esta cita podría considerarse un resumen de los puntos fundamentales de la relación entre el concepto de alma y las explicaciones teleológicas y mecánicas que se busca defender, pues se mencionan: i) la necesidad hipotética de cierta materia o elemento (el fuego) respecto del cumplimiento de

\footnotetext{
${ }^{11}$ Para el elemento finalista de la voz y la palabra, véase Pol I 2, 1253a10-15.
} 
determinada facultad del alma (la nutrición); ii) el alma como causa final, irreductible a la acción de la materia (el fuego); y finalmente iii) el alma como forma, esto es, definición que determina las funciones esenciales.

En suma, consideramos que este tipo de relaciones entre psicología, biología y metafísica expresan la consistencia metodológica del abordaje aristotélico de lo viviente, al tiempo que constituyen un marco teórico innovador y fructífero.

\section{La categoría de forma como superación del dilema entre mecanicismo $y$ vitalismo en la fenomenología merleau- pontyana}

- $\mathrm{n}$ esta sección analizaremos algunos de los principales conceptos

- de la fenomenología merleau-pontyana a la luz de la concepción aristotélica de lo viviente desarrollada en el apartado anterior, con el objetivo de argumentar en favor de una posible afinidad conceptual entre ambos en lo tocante a la irreductibilidad de los procesos orgánicos respecto de sus partes componentes. A tal efecto, es preciso destacar en primer lugar que el pensamiento de Merleau-Ponty surge como crítica a las gnoseologías modernas, donde el cuerpo es definido de manera residual, como "lo otro" de la conciencia, por lo que su estatuto ontológico es relegado a la categoría de objeto, y se supone pasible de ser explicado exhaustivamente por leyes naturales $^{12}$ (de modo análogo a lo que en el apartado anterior llamamos "necesidad material"). Por citar un ejemplo paradigmático, Descartes, en su Tratado del Hombre, explica la nutrición, la percepción, el movimiento e incluso los estados anímicos en términos exclusivamente mecánicos y concluye que los órganos son condición necesaria y suficiente para la comprensión de estas funciones, por lo que es innecesario postular un alma nutritiva o sensitiva; además, en expreso contraste con Reproducción de los animales (II 9, 736b30-737a15) y Acerca del alma (II 4, 416a10-20), sostiene que el calor del organismo es del mismo tipo que el de los cuerpos inanimados (Descartes 2003: 113). Dado el automatismo y la independencia de los procesos orgánicos, el alma resulta definida por $-\mathrm{y}$ reducida a- la acción de pensar (Descartes 2003: 114-115), es decir, al alma racional, distinguida por su apodicticidad, siendo el resto de las facultades aplicaciones o modos del pensamiento (Descartes 1996: 120-121). Esta redefinición del cuerpo es

${ }^{12}$ Véase Pagni 2012: 55. 
producto de la distinción sustancial entre res cogitans y res extensa establecida en las Meditaciones Metafísicas (Descartes 2004: 127-128).

Considerando esta breve referencia al sistema cartesiano, podría decirse que las formas modernas de dualismo se fundamentan en lo que en términos aristotélicos sería una reducción de psychế a noûs.

Frente a esta tradición, la fenomenología merleau-pontyana constituye una revisión detallada y crítica que explicita sus ambigüedades, deficiencias explicativas e hipótesis ad hoc producto de su inadecuación para dar cuenta del comportamiento de lo viviente. ${ }^{13}$ En este sentido, un aspecto destacable de las investigaciones del fenomenólogo -que puede interpretarse como coincidente con el postulado aristotélico de referir al alma en los estudios de biología- es que en La estructura del comportamiento y Fenomenología de la percepción, así como en La nature, sus análisis sobre la relación entre conciencia y naturaleza incluyen el comportamiento animal, explicitando la dimensión fáctica de conceptos como el de ser-del-mundo, cuya extensión se suponía restringida al existente humano (Merleau-Ponty 1984: 96-97; 1953: 105-106). Otro aspecto metodológico que resulta de fundamental importancia para las críticas al mecanicismo y al intelectualismo es el apoyo empírico de los casos patológicos analizados en ambas obras, por cuanto evidencian que incluso los abordajes reduccionistas refieren implícita e ineludiblemente a dimensiones afectivas, temporales o pragmáticas que se asumían incompatibles con el estatuto ontológico del cuerpo (Merleau-Ponty 1984: 117, 157, 166; 1953: caps. I y II). Por último, como consecuencia de las características mencionadas, Merleau-Ponty desarrolla una notable reivindicación de la originalidad del funcionamiento orgánico que, si bien rechaza explícitamente la idea de una causa final, prioriza las funciones frente a los sustratos anatómicos preestablecidos. Creemos que en este punto reside la mayor semejanza con el pensamiento aristotélico.

El análisis merleau-pontyano se propone tomar "al pie de la letra" (1984: 91) la reducción del cuerpo al estatuto de objeto derivada del dualismo, lo cual implica concebirlo como una yuxtaposición de partes exteriores las unas a las otras, entre las cuales solo hay relaciones causales y mecánicas, de manera que la explicación de sus funciones o procesos no requiere más que sustratos anatómicos y una causalidad lineal y unidireccional, no

\footnotetext{
13 “Aquí la idea no está introducida para volver inteligible el hecho mismo, sino para ocultar un desacuerdo visible entre la teoría y la experiencia. Puede decirse pues que las hipótesis auxiliares del control y de la inhibición están destinadas a mantener la teoría clásica del reflejo más que a hacer comprender positivamente la naturaleza de la actividad nerviosa." (Merleau-Ponty 1953: 39). Véase también Merleau-Ponty (1984: I, 1).
} 
diferente de la que rige los procesos fisicos ${ }^{14}$ (tal como Descartes sostiene en el Tratado del Hombre). La expresión más clara y acabada de este modelo dualista al momento en que Merleau-Ponty aborda la cuestión es la teoría clásica del reflejo.

En los dos primeros capítulos de La Estructura del Comportamiento, el fenomenólogo critica la reflexología como explicación de la percepción y los procesos orgánicos en general. Pues si se los reduce a un conjunto de excitaciones discretas y lineales entre los estímulos y el cerebro, a las que corresponde un sustrato anatómico preestablecido, no se explica cómo una respuesta varía dependiendo de la posición del cuerpo y de los estímulos simultáneos y precedentes:

Una misma excitación sobre el brazo de una estrella de mar provoca un movimiento hacia el punto excitado si el brazo está extendido sobre un plano horizontal y, por el contrario, un movimiento uniforme hacia el lado más tendido si el brazo descansa en falso. Un golpe bajo la rótula provoca en el hombre una reacción de extensión si la pierna interesada está cruzada sobre la otra, y una reacción de flexión si está extendida pasivamente. (Goldstein, K. cit. por Merleau-Ponty 1953: 43).

La variedad de ejemplos de este tipo permite al autor concluir que el organismo no responde a las propiedades puntuales de los estímulos aquellas que surgen del contacto entre partes exteriores- sino a propiedades formales como la frecuencia, la distribución espacial o la intensidad. ${ }^{15} \mathrm{Si}$, por el contrario, se insistiera en explicar este comportamiento basándose en los principios de la reflexología, sería necesario postular, para cada punto excitado, la confluencia en él de tantos circuitos nerviosos como posibles po-

14 “La definición del objeto es, según vimos, de que existen partes extra partes, y, por lo tanto, no admite entre sus partes, o entre él y los demás objetos, más que relaciones exteriores y mecánicas, ora en el sentido estricto de un movimiento recibido y transmitido, ora en el sentido lato de una relación de función a variable. Si se quería insertar el organismo en el universo de los objetos y cerrar con él a este universo, se precisaba traducir el funcionamiento del cuerpo en el lenguaje del en-sí y descubrir bajo el comportamiento la dependencia lineal del estímulo y del receptor, del receptor y del Empfinder." (Merleau-Ponty 1984: 92).

15 "La excitación misma es ya una respuesta, no un efecto importado del exterior al organismo, es el primer acto de su funcionamiento propio. La noción de estímulo remite a la actividad original por la cual el organismo recoge las excitaciones dispersas local y temporalmente en sus receptores y da una existencia corporal a esos entes de razón que son el ritmo, la figura, las relaciones de intensidad; en una palabra, la forma de conjunto de los estímulos locales". (Merleau-Ponty 1953: 54). Véase también (Merleau-Ponty 1953: 47). 
siciones resultantes, que excitarían ora una respuesta, ora otra diferente. Pero en ese caso sería preciso dar cuenta de cómo es que ante una excitación no se producen una multiplicidad de reacciones desordenadas e incoherentes, ya que no es lo que de hecho sucede. Para ello, la reflexología asume que mientras solo uno de los circuitos en cuestión actúa, el resto es inhibido por un centro de control. Mas esta respuesta solo traslada el problema, pues entonces habría que explicar dónde estaría ubicado dicho centro, y por qué inhibiría ciertas reacciones y permitiría otras, lo cual exigiría, a su vez, postular nuevos sustratos anatómicos preestablecidos (Merleau-Ponty 1953: 54-55, 77-81). Coincidimos con Moinat (2012: 97) en que una explicación semejante conlleva una regresión al infinito, resultado inaceptable también para el modelo de explicación aristotélico. ${ }^{16}$

Asimismo, el modelo de la reflexología resulta infalsable, como bien reconoce el autor:

El mecanismo de estimulaciones, inhibiciones y desinhibiciones que invoca, tiene necesariamente el aspecto de un expediente destinado a encubrir el desacuerdo entre la teoría y la experiencia, mientras no nos informemos en otra parte sobre los procesos de la fisiología cerebral. Una teoría que, sin apoyo experimental, supone fuerzas de sentido contrario, escapa evidentemente al desmentido de la experiencia, pues puede siempre hacer intervenir en determinado momento a uno de los dos principios, a falta del otro. (Merleau-Ponty 1953: 92).

Por otra parte, el rechazo de cualquier componente intencional o valorativo, o bien de fenómenos como regulación, compensación o equilibrio, ya sea en el comportamiento en general o en el funcionamiento de un órgano en particular, implica una degradación ontológica de su función, en tanto esta resulta ser un mero agregado de procesos mecánicos:

La fisiología clásica del reflejo exige que la función sea solo un producto o un resultado de las estructuras existentes; le niega, en suma, la realidad propia y objetiva: no es más que una manera humana de designar los efectos del mecanismo. (Merleau-Ponty 1953: 59).

Se trata de una consecuencia evidentemente antiaristotélica, teniendo en cuenta la prioridad ontológica que el filósofo reconoce a la función en el

${ }^{16}$ Véase Met $\alpha$ 2, 994a1-10. 
concepto de necesidad hipotética, lo que implica asimismo que la causa final efectivamente opera en la naturaleza, ${ }^{17} \mathrm{y}$ de ningún modo puede reducirse a un mero recurso explicativo para dar cuenta de los procesos orgánicos. ${ }^{18}$

Si bien Merleau-Ponty también rechaza las consecuencias mencionadas, el fundamento de su crítica al mecanicismo resulta innovador por cuanto refiere a casos patológicos que evidencian su deficiencia para dar cuenta de la propia experiencia del enfermo, al tiempo que destacan la plasticidad y orientación de las funciones orgánicas, componentes desestimados como antropomórficos por la teoría clásica del reflejo:

Si se determinan, por la medida del perímetro de visión, los sectores retinianos que permanecen capaces de provocar sensaciones luminosas en el hemianóptico, se comprueba que este solo dispone de dos semiretinas y podría esperarse, en consecuencia, que su campo visual correspondiera a la mitad (...) En realidad no es así; el sujeto tiene la impresión de ver mal, pero no de estar reducido a un semicampo visual. Es que el organismo se ha adaptado a la situación creada por la enfermedad, reorganizando el funcionamiento del ojo (...) Si nos atenemos a las concepciones clásicas que relacionan las funciones perceptivas de cada punto de la retina con su estructura anatómica (...) la reorganización funcional en la hemianopsia no es comprensible. Solo llega a serlo si las propiedades de cada punto retiniano le son asignadas no por dispositivos locales preestablecidos, sino por un proceso de distribución flexible. (Merleau-Ponty 1953: 66-68. Las cursivas son nuestras).

Con el ejemplo citado pretendemos mostrar que la atribución a los procesos orgánicos de propiedades como integración, equilibrio $\mathrm{u}$ orientación, así como la plasticidad de sus funciones para adaptarse a diferentes situaciones, no son meras proyecciones antropomórficas o recursos heurísticos capaces de reducirse a conjuntos de efectos de partes elementales. Por el contrario, coincidimos con Merleau-Ponty y Aristóteles en que se trata de propiedades que pertenecen objetivamente a tales procesos.

Considerando ejemplos como el referido, el fenomenólogo propone la categoría de forma para dar cuenta de aquellas reorganizaciones que exceden la causalidad mecánica, permitiendo que las propiedades o funciones de un sistema "se modifiquen por todo cambio aportado a una sola de sus partes, y se conserven por el contrario cuando cambian todas man-

${ }^{17}$ No por eso debe identificarse con la causa eficiente. Véase nota 9; $P A$ I 3, 640a20-25, 640b5-641a15; RA II 7, 735a1-5, V 2, 778b1-10, V 24, 789b1-20; Fís II 8, 199a20-30.

${ }^{18}$ Véase Gotthelf 1987: 228-229. 
teniendo entre sí la misma relación" (1953: 76).$^{19} \mathrm{La}$ "forma" en el sentido merleau-pontyano posee dos características que podrían considerarse semejantes a las del alma en Aristóteles, pues: i) no se reduce a sus elementos componentes (1953: 76), pero ii) no es independiente de los sustratos en los que se realiza (1953: 108 ss.). No obstante, una diferencia fundamental respecto del alma aristotélica radica en que la forma merleau-pontyana no tiene un carácter teleológico, es decir, no es un principio que orienta el desarrollo hacia una forma completa ontológicamente previa (determinada por el generador). ${ }^{20}$ Asimismo, Merleau-Ponty enfatiza que la forma no es una segunda causalidad que dirige o corrige el mecanicismo, y aunque posee una connotación finalista, no es más que la expresión de la unidad que realizan ciertos conjuntos naturales, lo cual implica que se trata de una propiedad descriptiva y no de un recurso explicativo (1953: 80-82).

Por otra parte, la afirmación de que el orden es una categoría descriptiva (Merleau-Ponty 1953: 80 ss.) brinda apoyo a la tesis de que la orientación o función de los procesos orgánicos no se fundamenta en una instancia trascendente a la naturaleza, sino que es una propiedad del organismo como totalidad. Teniendo en cuenta las conclusiones presentadas, coincidimos con Moinat (2012:104) en que La Estructura del Comportamiento puede pensarse como una epistemología de la biología en tanto aporta al estudio de lo viviente una ontología superadora de la teoría clásica del reflejo.

En este punto es importante destacar que el filósofo examinó con más detalle la adecuación del vocabulario finalista en la descripción de los procesos orgánicos. En sus cursos sobre la naturaleza analiza los estudios de Russell, quien sostuvo la necesidad de reconocer una finalidad en procesos como la regeneración de tejidos cuando se produce una herida. Por su parte, Merleau-Ponty matiza esta afirmación aclarando que si bien el aspecto finalista encuentra evidente apoyo empírico en el proceso de reparación y regeneración, dicho proceso puede interrumpirse modificando alguna condición (por ejemplo, si la herida se cubre con celofán) (Merleau-Ponty 1968: 234). Si bien este fenómeno no puede reducirse a reacciones de sus partes componentes, tampoco parece adecuado hablar de una finalidad en sentido fuerte o esencialista (Merleau-Ponty 1968: 203-204), tal como se encuentra

${ }^{19}$ Para la caracterización de la categoría de forma como superación de la dicotomía mental-fisiológico, y su relación con la idea de propiedad emergente, véase Thompson 2007: caps. 2 y 3 .

${ }^{20}$ Sobre este punto coincidimos con Balme (1987: 291-293) en que el desarrollo del embrión se dirige primariamente a la semejanza del generador en tanto individuo y accidentalmente a la semejanza de la especie. 
en los tratados biológicos de Aristóteles, sino más bien de una finalidad condicionada o, como dirá Merleau-Ponty, "ciega":

Un tejido proporciona, además de su estructura actual, otras posibles. Es una suerte de verificación experimental del aristotelismo: hay una causa formal más allá del mecanismo, una planificación victoriosa en cada fragmento del planar. Al mismo tiempo Russell señala que esta finalidad funciona de forma incondicional. Si se incide en planares, orientando las aperturas unas delante del animal y otras detrás, las regiones exclusivamente orientadas adelante dan lugar a la formación de una o de varias cabezas, y las otras a la regeneración de una cola. La finalidad del animal es ciega, no se ajusta a un plan de conjunto sino a condiciones locales. El organismo presenta una teleología limitada y especializada. (Merleau-Ponty 1968: 237-238. Las cursivas son nuestras).

A pesar de los matices aclarados, creemos que el reconocimiento de un desarrollo y funcionamiento que exceden las causas eficientes o mecánicas habilita a sostener una semejanza considerable respecto de la concepción aristotélica de lo viviente. Retomando los términos aristotélicos propuestos al comienzo de esta sección, la fenomenología merleau-pontyana en su conjunto podría interpretarse como un proyecto que se opone a la reducción de psychè a noûs, defendiendo, por el contrario, una ampliación de psyché a zōé. Pues si bien Merleau-Ponty atribuye a los procesos orgánicos -tanto en humanos como en otros animales- propiedades como adaptación, integración, orientación o equilibrio, cuya explicación excede el marco teórico mecanicista, es igualmente crítico del intelectualismo y del vitalismo, en la medida en que rechaza toda explicación de tales propiedades que recurra a una instancia ontológica independiente de lo sensible, reconociendo un orden que radica en los vivientes mismos (tanto a nivel comportamental como fisiológico). En este sentido consideramos que si bien las notas distintivas del concepto de forma, así como las restricciones a la noción de teleología lo distancian de Aristóteles ${ }^{21}$ el fenomenólogo reconoce a la naturaleza las mismas características que definen la posición del estagirita frente a sus predecesores, a saber: i) que la forma actual de los seres vivos no

${ }^{21}$ Con todo, la interpretación de la teleología propuesta por Gotthelf (1987: 228-229) podría considerarse como una conciliación con la posición merleau-pontyana: "La teleología aristotélica, de hecho, no es ni vitalista y mística, ni 'como si' y mecánica. La noción de una potencia de forma irreductible proporciona el contenido apropiado para el reconocimiento de que para Aristóteles el desarrollo orgánico efectivamente es directivo, sin que eso implique (...) que es dirigido". 
es producto del azar; ii) que la existencia y desarrollo de los procesos orgánicos no puede reducirse a sus partes componentes; y iii) que la existencia y desarrollo de los procesos orgánicos no obedece a una instancia trascendente a la naturaleza. Creemos que el siguiente pasaje resume y atestigua las características mencionadas:

Al hablar aquí de conocimiento y por consiguiente de conciencia, no construimos una metafisica de la naturaleza (...) Al reconocer que los comportamientos tienen un sentido y dependen de la significación vital de las situaciones, la ciencia biológica se prohíbe concebirlos como cosas en sí que existirían, partes extra partes, en el sistema nervioso o en el cuerpo (...) No se trata, como ya hemos dicho suficientemente, de volver a una forma cualquiera de vitalismo o de animismo, sino simplemente de reconocer que el objeto de la biología es impensable sin las unidades de significación que una conciencia en él encuentra y ve desplegarse. Así, pues, en realidad, ya hemos introducido la conciencia y lo que hemos designado con el nombre de vida era ya la conciencia de la vida. (Merleau-Ponty 1953:227-228. Las cursivas son nuestras.)

\section{Conclusión}

$\mathrm{P}$ resentamos la causa final como un elemento central e innovador de la filosofía de Aristóteles respecto de sus predecesores. Considerando la aparente incompatibilidad entre necesidad material y teleología, explicamos brevemente cómo pueden articularse gracias a las nociones de necesidad hipotética y función. Asimismo, enfatizamos que la compatibilidad entre mecanicismo y teleología se fundamenta en el concepto de alma o esencia como un aspecto indispensable para el estudio de la naturaleza, pues en tanto definición de las funciones esenciales del ser vivo, determina qué órganos habrán de formarse, y consecuentemente qué elementos -y qué proporción de los mismos- tendrán lugar en el desarrollo del viviente. Por último, reconocimos que la referencia entre los tratados biológicos y Acerca del Alma, Física y Metafísica, revelan tanto la consistencia metodológica con que Aristóteles emprende el análisis de lo viviente, como un marco teórico adecuado a las propiedades atribuidas al objeto de estudio. Reteniendo el aspecto irreductible de los procesos orgánicos y la prioridad ontológica de las funciones, presentamos algunas tesis de la fenomenología merleau-pontyana que podrían considerarse solidarias respecto de la concepción aristotélica de lo viviente. Específicamente, la categoría de forma, que surge de las críticas al mecanicismo y al vitalismo en La Estructura del Comportamiento, así como el análisis de la teleología en La Nature, habilitan a reconocer en 
Merleau-Ponty la postulación de un orden en la naturaleza que no puede explicarse por sus partes componentes, pero que tampoco depende de una instancia intelectual independiente de ellas.

\section{BIBLIOGRAFÍA}

Aristóteles (Fís), Física (Madrid: Gredos, 1995).

Aristóteles (Met), Metafísica (Madrid: Gredos, 1994).

Aristóteles (PA), Partes de los Animales (Madrid: Gredos, 2000).

Aristóteles (Pol), Política (Buenos Aires: Prometeo, 2015).

Aristóteles (RA), Reproducción de los Animales (Madrid: Gredos, 1994).

Aristóteles (1978), Acerca del alma (Madrid: Gredos).

Aristóteles (2010), Acerca del alma (Buenos Aires: Colihue).

Balme, D. M. (1939), "Greek Science and Mechanism I: Aristotle on Nature and Chance”, The Classical Quarterly, 33: 129-138.

Balme, D. M. (1987), “Aristotle's Biology was not Essentialist”, en A. Gotthelf y J. Lennox (1987) (eds.), Philosophical Issues in Aristotle's Biology (New York: Cambridge University Press, 291-312).

Boylan, M. (1981), "Mechanism and Teleology in Aristotle's Biology”, Apeiron, 15: 96-102.

Cooper, J. M. (1987), "Hypothetical Necessity and Natural Teleology”, en A. Gotthelf y J. Lennox (1987) (eds.), Philosophical Issues in Aristotle's Biology (New York: Cambridge University Press, 243-274).

Descartes, R. (1996), Reglas para la dirección del entendimiento (Madrid:Alianza).

Descartes, R. (2003), Treatise of Man (New York: Prometheus Books).

Descartes, R. (2004), Meditaciones Metafísicas (Buenos Aires:Terramar).

Fóti, M.V. (1999), "Merleau-Ponty's Vertical Genesis and the Aristotelian Powers of the Soul”, en B. Hopkins (1999) (ed.), Phenomenology: Japanese and American Perspectives (Dordrecht: Springer, 39-58). https://doi.org/10.1007/978-94-017-2610-8_3.

Gotthelf, A. (1987), “Aristotle's Conception of Final Causality”, en A. Gotthelf y J. Lennox (1987) (eds.), Philosophical Issues in Aristotle's Biology (New York: Cambridge University Press, 204-242).

Gotthelf, A. y Lennox, J. (1987) (eds.), Philosophical Issues in Aristotle's Biology (New York: Cambridge University Press).

Honorato, D. (2018), "El fenómeno de la percepción en Aristóteles y Merleau-Ponty", Ideas y Valores, 67,166: 13-48.

Hopkins, B. (1999) (ed.), Phenomenology: Japanese and American Perspectives (Dordrecht: Springer).

Merleau-Ponty, M. (1953), La estructura del comportamiento (Buenos Aires: Hachette).

Merleau-Ponty, M. (1968), Nature: Course Notes from the Collège de France (Evanston: Northwestern University Press). 
Merleau-Ponty, M. (1984), Fenomenología de la percepción (Madrid: Planeta-Agostini).

Moinat, F. (2012), Le vivant et sa naturalization: le problème du naturalisme en Biologie chez Husserl et le jeune Merleau-Ponty (Dordrecht, Heidelberg, London, New York: Springer).

Pagni, E. (2012), Corpo vivente mondo: Aristotele e Merleau-Ponty a confronto (Firenze: Firenze University Press).

Platón Timeo, en Diálogos VI (Madrid: Gredos, 1992).

Stevens, A. (2002), "Comment Merleau-Ponty renouvelle-t-il l'ontologie de la perception héritée d'Aristote?”, Les Études Philosophiques, 62: 317-331.

Thompson, E. (2007), Mind in Life: Biology, Phenomenology and the Sciences of Mind (Cambridge, Massachusetts, London: Harvard University Press).

Recibido: 06-03-2019; aceptado: 23-07-2019 